\title{
Home range and activity patterns of the coral trout Plectropomus leopardus (Serranidae)
}

\author{
Dirk C. Zeller \\ Department of Marine Biology, James Cook University of North Queensland, Townsville, Queensland 4811, Australia
}

\begin{abstract}
Patterns of movement and space utilization by fishes are becoming increasingly important to the understanding of population dynamics, community structure and spatial population models. Despite this, information regarding patterns of movement is rare for fishes. The aim of this study was to determine home ranges and basic temporal patterns of space use of Plectropomus leopardus (Serranidae), a species of major fishing importance on coral reefs. Thirty-nine individual $P$. leopardus (size range: 37.6 to $67.5 \mathrm{~cm}$ FL) were tracked successfully via ultrasonic telemetry between 1993 and 1995 Eight of these were tracked during 2 subsequent field trips, resulting in 47 separate tracking sessions, comprising a total of 2024 fish-tracking days. Average minimum area polygon home ranges of $P$. leopardus differed between fish from continuous fringing reefs $\left[10458.4 \mathrm{~m}^{2} \pm 962.3\right.$ (SE)] and isolated patch reefs [18796.9 $\mathrm{m}^{2} \pm 3188.8$ (SE)], and were due to differences in widths of home ranges, with fringing reef home ranges being narrower than patch reef ones, Lengths of home ranges did not differ between reef types. Home ranges did not differ between male and female fish, and were stable within and between each tracking session (maximum $202 \mathrm{~d}$ between sessions). P. leopardus were diurnally active, regularly using a small number of physical locations ( 3 or 4 ) within their home ranges. Mean daily distance moved within home ranges was $192.2 \mathrm{~m} \pm 5.09$ (SE), with the maximum being $1121.8 \mathrm{~m}$. Patterns of space use were relatively consistent throughout the day. Location fidelity was very high at night, and reflected limited movements by the fish. The present data document for the first time the home range of a large coral reef serranid, and illustrate its preference for a small number of locations within a larger home range area. Ultrasonic telemetry is the most suitable tool for evaluation of home ranges and movements of large reef fishes. This has implications for the acquisition of data required for the evaluation of marine reserves as fisheries management tools for coral reefs.
\end{abstract}

KEY WORDS: Activity patterns - Coral reef fish - Fisheries management - Home ranges - Marine reserves - Plectropomus leopardus - Serranidae - Ultrasonic telemetry

\section{INTRODUCTION}

The patterns of movement and space use by an individual can be considered one of the most fundamental demographic parameters which influence ecological patterns of populations, communities and species (Cameron \& Spencer 1985, Andrew \& Mapstone 1987, Gregory et al. 1987). Lately, the use of marine reserves has been proposed as the most viable strategy for sustainable management of coral reef fisheries (Alcala \& Russ 1990, Bohnsack 1990, 1993, Polacheck 1990, DeMartini 1993, Rowley 1994, Russ \& Alcala 1996a, b).

•E-mail: dirk.zeller@jcu.edu.au
General acceptance of such a strategy by local fishing communities, particularly in the developing world, may depend on the determination of potential flux rates of target species across reserve boundaries ( the 'spillover' effect) and the impact of such fluxes on local fisheries yield (Alcala \& Russ 1990, Bohnsack 1990, Russ \& Alcala 1996a, b). Transfer rates of animals between protected and unprotected areas are influenced to a large extent by the reserve boundary permeability (Buechner 1987), as well as the size of the protected area relative to the normal movement patterns and home ranges of the target species (Holland et al. 1993a, 1996). Thus, the concept of 'spillover' has, as one of its most basic parameters, the principle of home range size, as well as basic activity and movement pat- 
terns (Minns 1995). Despite its acknowledged importance, such basic information is rare for tropical marine fishes. Until recently, most studies concerning home range and activity patterns in fishes have been undertaken in lakes and rivers (e.g. Keeley \& Grant 1995, Minns 1995). In the tropical marine environment, studies which address space use by fishes have generally concentrated on small, easily observed reef fishes such as pomacentrids and labrids (review by Sale 1991) and acanthurids (Robertson \& Gaines 1986). More recently, investigations of home ranges included studies of larger species, e.g. Mullidae (Holland et al. 1993a), Haemulidae (Tulevech \& Recksiek 1994), Carangidae (Holland et al. 1996), and sharks (Nelson 1990, Holland et al. 1992, 1993b, Morrissey \& Gruber 1993).

Members of the family Serranidae are considered to be among the most abundant predatory fishes in warm water regions (Randall 1963, Nagelkerken 1979), and often form a major component of fisheries' catches (Sadovy 1994, Williams \& Russ 1994). Despite their economic significance, relatively little is known about the habitat and space usage patterns of these fishes (Moe 1969, Hobson 1974, Munro 1974, Thompson \& Munro 1978). Some behavioural work has been done on serranids, mainly on the smaller epinephelids (Shpigel \& Fishelson 1989a, b, 1991a, b) and Anthias (Shapiro 1986). Basic home range estimates for larger serranids are rare, and are often based on limited observations (Bardach 1958, Springer \& McErlean 1962, Carter 1988). Some attempts at home range estimation using ultrasonic telemetry have been made for the Nassau grouper Epinephelus striatus (Carter et al. 1994).

The coral trout Plectropomus leopardus forms the primary target of the commercial and recreational line fishery on the Great Barrier Reef in Australia (Williams \& Russ 1994). Despite the importance of this species, investigations into space use patterns have received very limited attention. To date, the 2 principle studies attempting to investigate home ranges in P. leopardus were based on visual observations of marked (Samoilys 1987) or even unmarked individuals (Goeden 1978). However, some methodological concerns arise from these studies. Firstly, the close physical presence of a diving observer during these investigations may have resulted in observer disturbance of $P$. leopardus. Furthermore, the time periods of actual observations were very small ( 7 to $120 \mathrm{~min}$, Goeden 1978), or estimations of home ranges were based on ratios of resighting and not resighting tagged fish within a limited study area (Samoilys 1987). Movements of $P$. leopardus within a $4 \mathrm{~km}$ section of reef at Heron Island (Great Barrier Reef, Australia) were reported also by Beinssen (1989). His study found that $29 \%$ of resighted coral trout had moved out of the initial $500 \mathrm{~m}$ long reef slope release site within $3 \mathrm{wk}$. Davies (1995), as part of a mark-release-recapture study using fish traps, documented the largest recorded movements of $P$. leopardus as being $415 \mathrm{~m}$ (17 recaptures from 65 tagged specimens). In a related study, Davies (1995), using commercial fishers, tagged 4627 P. leopardus on a cluster of 5 neighbouring reefs in the central section of the Great Barrier Reef. During 5 sampling trips spread over a 2 yr period, the majority of recaptured fish $(74 \%, \mathrm{n}=143)$ were recovered within their 2.0 to $2.5 \mathrm{~km}$ long reef section of release. In all of these studies, while occasional large movements were observed, the vast majority of movements seemed to be restricted to between 200 and $400 \mathrm{~m}$.

Technological developments since the early studies by Goeden (1978) and Samoilys (1987) have resulted in the commercial availability of reliable ultrasonic telemetry systems. Such systems make a remote tracking approach to the study of basic home ranges and activity patterns possible. This approach overcomes the inherent shortcomings of visual observations (observer disturbance and SCUBA limitations), and provides a more reliable and accurate estimate of home ranges. Few attempts have been made to use ultrasonic telemetry on coral reef fish (Holland et al. 1993a, 1996), with most studies concentrating on sharks (Nelson 1990, Holland et al. 1992, 1993b, Morrissey \& Gruber 1993).

The aims of this study were to utilise ultrasonic telemetry as a non-intrusive, remote monitoring technique to: (1) provide the first unequivocal documentation of the size of home ranges of Plectropomus leopardus; (2) investigate the basic activity patterns of $P$. leopardus; and (3) address the temporal stability of the home ranges of $P$. leopardus over a maximum period of $1 \mathrm{yr}$.

\section{MATERIALS AND METHODS}

This study was conducted at Lizard Island, northern Great Barrier Reef, Australia $\left(14^{\circ} 40^{\prime} \mathrm{S}, 145^{\circ} 28^{\prime} \mathrm{E}\right)$. Ultrasonic tracking of Plectropomus leopardus was undertaken during 5 tracking sessions spanning 1 to 3 mo each between January 1993 and December 1995. The capture and release locations of tracked specimens were distributed over a large area around Lizard Island (Fig. 1), in order to utilise specimens from both patch and fringing reef habitats, and to avoid ultrasonic signal overlap from transmitters on the same frequency, which would make correct identification of individuals and correct determination of physical locations more difficult (Zeller 1997). Specimens of P. leopardus were captured on hook and line, and released at their capture sites after successful recovery from surgi- 


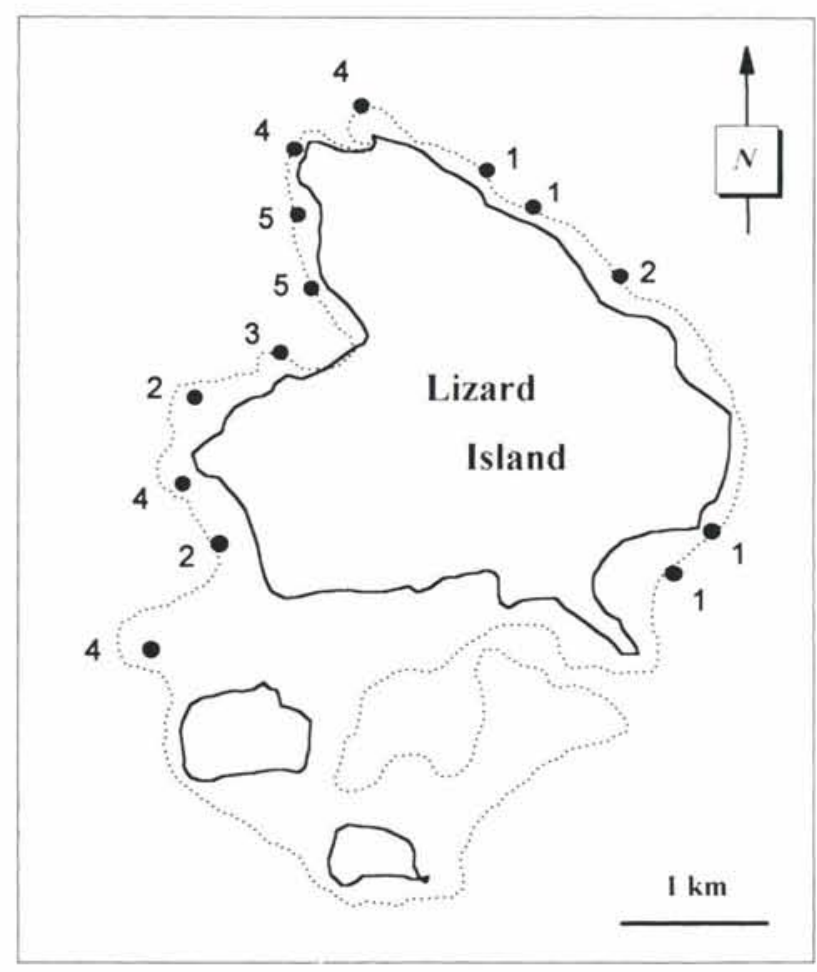

Fig. 1. Plectropomus leopardus. Locations of fish tracked with ultrasonic telemetry between 1993 and 1995 around Lizard Island (northern Great Barrier Reef, Australia). Dotted lines indicate general reef contour outlines. Locations of tracking specimens around the island are indicated $(\bullet n=39)$. Numbers associated with locations indicate the number of specimens tracked at that location. Prevailing wind direction is from the southeast

cal insertion of ultrasonic transmitters (Vemco V8, V16 or Sonotronics Xtal) into the body cavity. Surgical placement of transmitters, subsequent aquaria recovery periods and the general tracking techniques followed the methods described by Holland et al. (1985), Mortensen (1990) and Zeller (1997). Position monitoring of specimens commenced immediately after release using a manual surface receiver (Vemco VR60) with directional hydrophone. Data collected during the first $24 \mathrm{~h}$ were considered to represent an acclimation period, and were not included in any subsequent analyses. Specimens were monitored daily with each fish being located at least 3 to 4 times per day for the duration of each tracking period. At the end of the expected battery life of the transmitter or at the termination of each tracking period, specimens were collected by speargun for sex-determination (sensu Ferreira 1995) and for recovery of transmitters.

Home range estimates and space use patterns. The minimum convex polygon (Jennrich \& Turner 1969), which represents a non-statistical measure of dispersion over the total area used by an individual, was cho- sen as the measure of home range area (Winter \& Ross 1982). Home ranges were measured from a minimum area convex polygon drawn around all position records, excluding positions recorded during the first day after release (acclimation period), positions recorded only once during the tracking period, and movements clearly associated with annual spawning aggregation events (see Zeller 1997). In addition to the area measure of the polygon, 2 linear dimensions were calculated: (1) the maximum linear dimension, defined as the largest diagonal of the home range area and being indicative of the length of each home range area, and (2) the minimum linear dimension, defined as the largest width of the polygon, measured perpendicular to the maximum linear dimension.

Measures of available reef area and average densities of coral trout in the areas occupied by each tracked specimen were determined in order to evaluate factors likely to influence the home range estimates. Available reef area $\left(\mathrm{m}^{2}\right)$ to the $20 \mathrm{~m}$ depth contour or to the reefsand interface was determined for patch reef habitats. Given the contiguous nature of fringing reef habitats, the most appropriate measure of available reef habitat was the average width of the fringing reef in the area of occupancy of an individual fish, calculated from 3 width measurements per home range. Width of the fringing reef was measured from the Lowest Astronomical Tide Datum (0 m Datum) to the $20 \mathrm{~m}$ depth contour or to the reef-sand interface, whichever came first. All estimates of reef parameters were digitised from calibrated aerial photos with overlaid depth contours (Sunmap, Queensland State Government, Australia). The density estimates of coral trout used as a variable in the home range parameter evaluation were obtained from underwater visual census data collected in 1995 as part of a related study (Zeller 1997).

Visual examination of usage patterns of home ranges were undertaken using percentage utilisation distributions calculated using the adaptive kernel method (Cameron \& Spencer 1985, Worton 1987). Adaptive kernel estimates were not used for statistical purposes. The $50 \%$ and $75 \%$ contours were taken as indicating the core area of activity, i.e. the geographic locations within the home range of greatest use.

Some of the more readily used locations recorded for tracked specimens were investigated via SCUBA. Wherever possible these positions were assigned to 1 of 3 habitat types: 'shelter sites', 'current pressure points/potential feeding sites' or 'cleaning stations of Labroides spp.' 'Shelter sites' were defined as clearly identifiable caves, overhangs or crevices used by the tracked specimen during the observation period, while 'pressure/feeding sites' related to visual observation of currents encountering reef structures, often associated with concentrations of planktivorous fishes (e.g. Poma- 
centridae and Caesionidae). 'Cleaning station' was assigned only if actual cleaning behaviour by Labroides spp. was observed, and neither of the other 2 habitat types could be assigned.

To assess potential shifts in the home ranges of individuals through time, linearity ratios were calculated for each tracked specimen (Bell \& Kramer 1979 in Danielson \& Swihart 1987). This is the ratio of distance between an individual's first and last recorded position and the total distance moved during the complete tracking period of each individual. It thus represents a measure of directedness of movements, with values being small if movements are back and forth, and unity if movements are unidirectional. In order to evaluate the persistence of home ranges over longer time periods, several fish were tracked over 2 separate time periods.

Analysis of data. The spatial position data obtained through ultrasonic tracking were digitised from calibrated aerial photos. All home range parameters were calculated using CALHOME ${ }^{\circ}$ (Kie et al. 1996), WILDTRACK $^{\circ}$ (Todd 1993) or SAS ${ }^{\circ}$ executable program routines written by White \& Garrott (1990). Incremental area analysis using a randomised temporal order of fixes for each specimen was undertaken on the telemetry data to determine which tracked specimens provided robust estimates of home range areas (Kenward 1987). Home range estimates were only included if the range estimates stabilised with increasing sample sizes. Statistical analyses used were $t$-tests, analysis of variance (ANOVA), analysis of covariance (ANCOVA), and linear and multiple regression techniques. All data were examined for violations of underlying statistical assumptions prior to analysis (Sokal \& Rohlf 1981, Underwood 1981) and data $\log _{10}$-transformed where applicable. Ratio data were analysed using natural log transformations (Underwood 1981).

\section{RESULTS}

A total of 39 Plectropomus leopardus (fork length, FL: mean $=49.0 \mathrm{~cm}$, range $=37.6$ to $67.5 \mathrm{~cm}$ ) were tracked successfully between 1993 and 1995, providing sufficient data for asymptotic home range stabilisation (Kenward 1987). The incremental area analysis indicated that robust home range estimates were achieved with 48 to 140 fixes. Of the 39 specimens, 8 were tracked during 2 subsequent field trips. This resulted in 47 separate tracking sessions, comprising a total of 2024 fish-tracking days and 8002 individual position fixes.

Initial examination of home ranges revealed obvious differences in the general shape of home ranges for fish from the 2 different reef types represented at
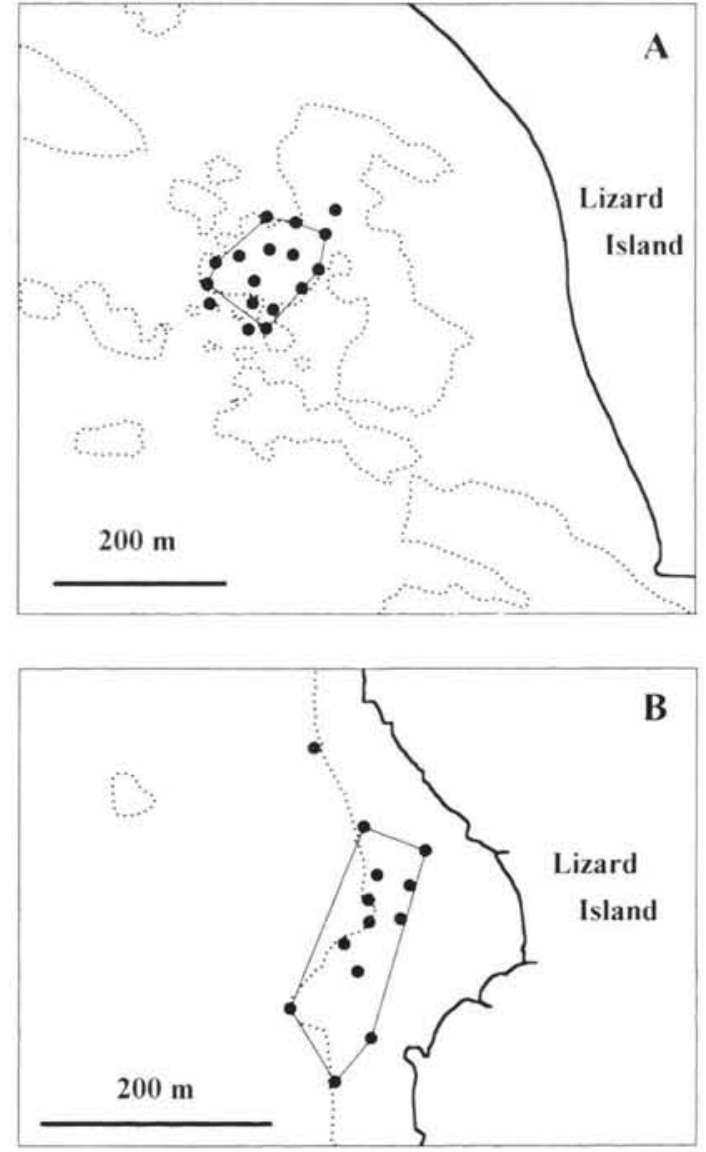

Fig. 2. Plectropomus leopardus. Representative home ranges, illustrating the differences in general shape of home ranges in the 2 reef habitat types. ( $\bullet$ Position records for each fish. Polygon outline: polygon home range outline. Dotted lines represent reef contour outlines. (A) Patch reef fish (tracking period $=120 \mathrm{~d}$ ). $(\mathrm{B})$ Fringing reef fish (tracking period $=46 \mathrm{~d}$ ). Note the more elongated home range

Lizard Island (isolated patch reef: Fig. $2 \mathrm{~A}_{\text {; }}$ contiguous fringing reef: Fig. 2B). Treating the differences in sizes of individual fish (FL) and sample sizes per home range estimate (number of fixes per estimate) as covariates, a significant difference was detected in the mean polygon home range area between the 2 dominant reef types $\left(\right.$ ANCOVA, $\left.F_{1,43}=9.37, \mathrm{p}=0.0038\right)$. Home range areas of Plectropomus leopardus were on average $44.36 \%$ larger on patch reefs $\left[18796.9 \mathrm{~m}^{2} \pm 3188.8\right.$ (SE)] than on fringing reefs [10458.4 $\mathrm{m}^{2} \pm 962.3$ (SE); Fig. $3 \mathrm{~A}$ ]. Comparison of the maximum linear diagonal dimension of home ranges (i.e. length) between the 2 reef types indicated that the lengths of home ranges did not differ between fish on fringing and patch reef (ANCOVA, $F_{1.43}=0.66, \mathrm{p}=0.4188$, mean $=223.0 \mathrm{~m} \pm$ $10.5 \mathrm{SE}$, range: $118.9 \mathrm{~m}$ to $376.9 \mathrm{~m}$ ). However, as would be expected from Fig. 2, the minimum linear dimension (i.e. width) did differ between reef types (ANCOVA, 

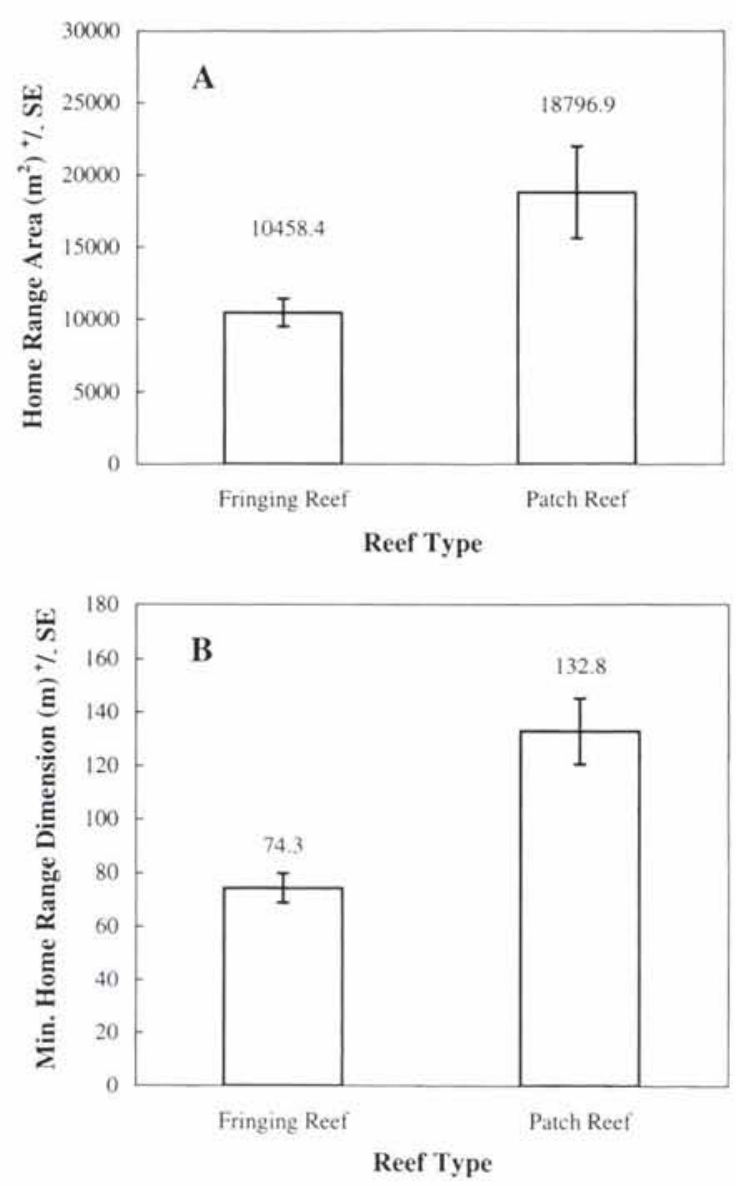

Fig. 3. Plectropomus leopardus. Differences in home range parameters between fringing and patch reefs for fish tracked by ultrasonic telemetry. Plotted are means \pm SE (fringing reefs: $n=29$ tracking sessions; patch reefs: $n=18$ tracking sessions), and mean values are presented numerically. (A) Mean area of convex polygon home range. (B) Mean minimum linear home range dimension (home range width)

$\left.F_{1,43}=24.97, \mathrm{p}=0.00001\right)$. On average, home ranges of $P$. leopardus were 1.78 times wider on patch reefs than on fringing reefs (Fig. 3B).

Assessment of differences in home ranges between male and female specimens was restricted to 32 individual tracking sessions, based on 26 fish (13 male and 13 female) that could be recovered for gender determination. Analyses of covariance, using fork length and tracking sample size as covariates, indicated that there were no significant differences in area, or in maximum or minimum linear dimensions of home ranges between male and female Plectropomus leopardus $\left(F_{1,28}=3.26, \mathrm{p}=0.0817 ; F_{1,28}=1.78, \mathrm{p}=0.1939 ; F_{1,28}=\right.$ $0.88, p=0.3551$, respectively). However, graphical examination of home range parameters indicated a tendency towards larger home ranges for male coral trout, particularly for the area measurement of home range (Fig. 4).
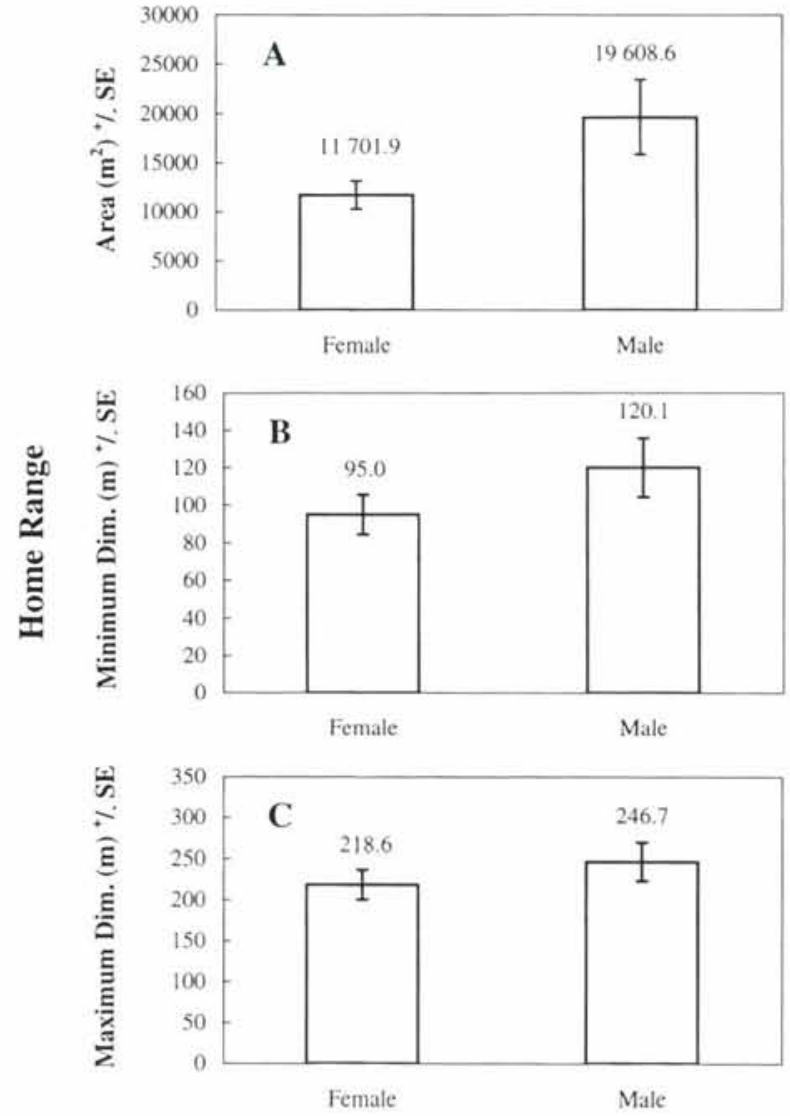

Fig. 4. Plectropomus leopardus, Comparison between females $(\mathrm{n}=13)$ and males $(\mathrm{n}=13)$ tracked by ultrasonic telemetry for the 3 home range parameters examined. Plotted are mean $\pm \mathrm{SE}$, and mean values are presented numerically. (A) Polygon home range area. (B) Minimum linear home range dimension (width). (C) Maximum linear home range dimension (length)

Evaluation of the relationships between the 3 home range parameters (area, maximum and minimum dimensions) and size of individual fish, local trout densities, tracking sample size and the measure of available reef dimension (patch reef area or fringing reef width) for both habitat types revealed some clear patterns for the patch reef habitat (Table 1). For Plectropomus leopardus on patch reefs, home range area (adjusted $\mathrm{r}^{2}$ $\left.=0.8423, F_{4,13}=23.0, \mathrm{p}<0.0001\right)$, maximum dimension (adjusted $\mathrm{r}^{2}=0.6666, F_{4,13}=9.49, \mathrm{p}<0.0008$ ), as well as minimum dimension (adjusted $\mathrm{r}^{2}=0.6299, F_{4,13}=8.24$, $\mathrm{p}<0.0015)$ displayed strong relationships with the variables examined. Specifically, $73.72 \%, 58.60 \%$, and $49.25 \%$ of variability in home range area, maximum, and minimum dimension, respectively, were explained by total available reef area (Table 1). Neither local trout density nor sample size contributed significantly to the relationships. The size of fish (FL) did make a significant contribution to the relationship with minimum home range dimension, explaining $31.05 \%$ of 
Table 1. Multiple regressions of the 3 home range parameters (area, length and width) against the variables 'available reef area', 'fish size (FL)', 'tracking sample size' and 'local trout densities', for Plectropomus leopardus living on patch reefs. Shown are overall regression p-values and adjusted $r^{2}$, as well as p-values for the individual variables and the percentage of variability in home range parameters explained by each variable, based on partial correlation coefficients

\begin{tabular}{|c|c|c|c|c|c|c|}
\hline & \multicolumn{3}{|c|}{ p-values } & \multicolumn{3}{|c|}{ Adjusted $r^{2}$} \\
\hline & Area & Length & Width & Area & Length & Width \\
\hline Overall regression & $<0.0001$ & $<0.0008$ & $<0.0015$ & 0.8423 & 0.6666 & 0.6299 \\
\hline Variables & & & & \multicolumn{3}{|c|}{$\%$ variability explained } \\
\hline Reef area & 0.0000 & 0.0009 & 0.0035 & 73.72 & 58.60 & 49.25 \\
\hline $\mathrm{FL}$ & 0.8198 & 0.2429 & 0.0309 & 0.41 & 10.32 & 31.05 \\
\hline Sample size & 0.6358 & 0.2655 & 0.3099 & 1.78 & 9.43 & 7.91 \\
\hline Trout density & 0.8055 & 0.3943 & 0.2162 & 0.48 & 5.64 & 11.51 \\
\hline
\end{tabular}

Table 2. Multiple regressions of the 3 home range parameters (area, length and width) against the variables 'available reef area', 'fish size (FL)', 'tracking sample size' and 'local trout densities', for Plectropomus leopardus living on fringing reefs. Shown are overall regression p-values and adjusted $r^{2}$, as well as p-values for the individual variables and the percentage of variability in home range parameters explained by each variable, based on partial correlation coefficients

\begin{tabular}{|c|c|c|c|c|c|c|}
\hline & \multicolumn{3}{|c|}{ p-values } & \multicolumn{3}{|c|}{ Adjusted $r^{2}$} \\
\hline & Area & Length & Width & Area & Length & Width \\
\hline Overall regression & $<0.0000$ & 0.2259 & 0.0007 & 0.7150 & 0.0700 & 0.4595 \\
\hline Variables & & & & \multicolumn{3}{|c|}{$\%$ variability explained } \\
\hline Reef area & 0.0000 & 0.0600 & 0.0009 & 65.52 & 13.97 & 37.57 \\
\hline FL & 0.0426 & 0.7971 & 0.0814 & 16.04 & 0.28 & 12.12 \\
\hline Sample size & 0.0034 & 0.3248 & 0.3757 & 30.56 & 4.04 & 3.28 \\
\hline Trout density & 0.2153 & 0.9128 & 0.0260 & 6.32 & 0.05 & 18.99 \\
\hline
\end{tabular}

variability ( $\mathrm{p}=0.0309$; Table 1$)$. Thus, these data suggest strongly that, for patch reef environments, coral trout home ranges (measured as area, maximum, or minimum dimension) are strongly positively correlated with total available patch reef area. The minimum dimension (i.e. width) of home ranges of coral trout living on patch reefs is furthermore influenced by the size of the fish. Hence, the larger the patch reef on which coral trout live, the larger the observed area, length and width of home ranges. However, larger coral trout manage to establish wider home ranges on patch reefs than smaller fish.

For fringing reef habitats the situation was not as clear. The relationship between home range area and the independent variables of reef dimension (fringing reef width), local trout density, fish size and home range sample size was significant (adjusted $r^{2}=0.7150$, $F_{4.24}=18.56, \mathrm{p}<0.0000$ ). Only local trout density did not contribute significantly to the relationship $(\mathrm{p}=$ 0.2153; Table 2). Reef width alone accounted for most of the observed variability in home range area $(65.52 \%$; Table 2$)$. No detectable relationship existed between the maximum linear dimension of home ranges and the variables examined (adjusted $\mathrm{r}^{2}=$ $0.0700, F_{4.24}=1.53, \mathrm{p}=0.2259$ ). However, reef width, as well as local trout densities accounted for significant variation in the minimum home range dimension (adjusted $\mathrm{r}^{2}=0.4595, F_{4.24}=6.95, \mathrm{p}<0.0007$ ). Reef width explained $37.57 \%$, and local trout densities $18.99 \%$ of observed variability in home range width (Table 2). Thus, while the length of home ranges of coral trout inhabiting fringing reefs appeared not to be influenced by any of the factors examined, the observed area and width of home ranges were primarily, but not exclusively, influenced by available fringing reef width.

\section{Activity patterns}

During the first ultrasonic tracking period in AugustOctober 1993, 6 individual Plectropomus leopardus were monitored for day/night activity patterns. Position records for 60 fish-nights were obtained, with 128 


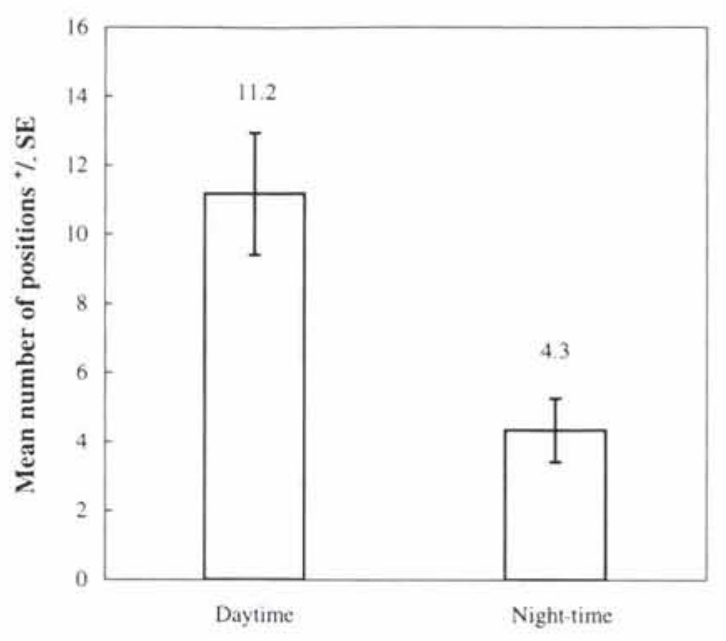

Time Period

Fig. 5. Plectropomus leopardus. Mean number $( \pm \mathrm{SE})$ of locations used during daytime and night-time tracking periods. Comparison was based on the 1993 tracking period ( $\mathrm{n}=6$ fish), as night-time tracking was discontinued thereafter

night-time position records out of a total of 689 records for the August-October 1993 period. On average, $P$. leopardus utilised fewer positions at night than during the daytime $\left(F_{1,10}=11.65, p=0.006\right.$, Fig. 5$)$, and the most commonly used night-time positions were also some of the most regularly frequented locations during the daytime. No positions were used exclusively at night. Visual examination of recorded positions on SCUBA revealed that 7 of the 13 most commonly used night-time positions for all 6 fish had pronounced crevices, overhangs or caves. Position fidelity at night was very high, with no nocturnal change in positions occurring on $88.3 \%$ of all monitored nights. On only $11.7 \%$ of nights did a fish change its position once during the night. The mean distance moved during nocturnal relocations was $58.3 \mathrm{~m}$ (median $=42.4 \mathrm{~m}$, range: 39.3 to $114.6 \mathrm{~m}$ ). Based on these observations, it was concluded that nocturnal activity by $P$. leopardus was minimal, and all subsequent tracking periods were restricted to daylight hours only.

Considering daytime data only, and combining all 47 separate tracking periods $(n=31$ fish with single tracking period, plus $\mathrm{n}=8$ fish with 2 separate tracking periods), coral trout were observed to utilise a mean of $12.1 \pm 0.55$ (SE) positions per individual fish (range: 5 to 19 positions/fish). The mean number of 'most commonly used' positions (i.e. positions contributing $\geq 10 \%$ of records/fish) recorded for Plectropomus leopardus was $3.5 \pm 0.18$ (SE) per individual fish. This can be illustrated by the adaptive kernel utilisation distributions (Fig. 6). Typically, 2 or 3 positions accounted for $50 \%$ of all observations made during the tracking period, while $75 \%$ of all tracking records for each fish

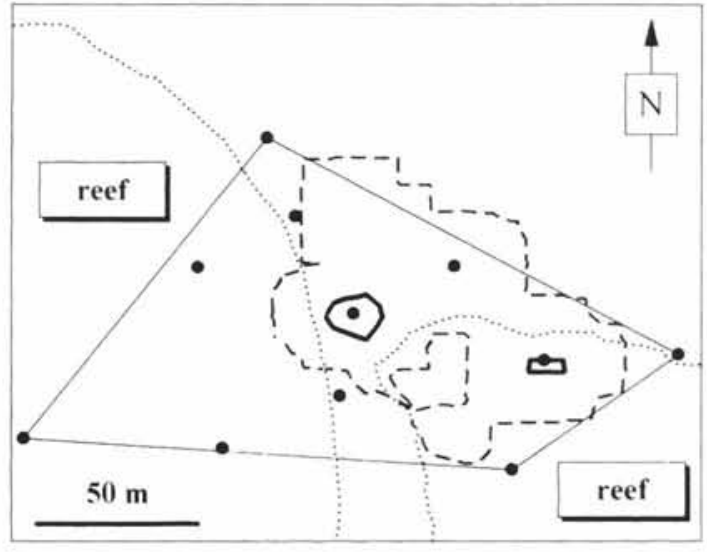

Fig. 6. Plectropomus leopardus. Percentage utilisation distributions of a representative individual inhabiting a patch reef area, illustrating the preference for a small number of locations. Polygon home range is indicated. Dotted line: reef contour outlines. (•) Position records. Dashed lines: $75 \%$ utilisation distribution contour. Solid lines: $50 \%$ utilisation distribution contour

were obtained from 3 or 4 positions within their respective home ranges (Fig. 6).

In order to evaluate potential differences in home range usage patterns throughout the day, the number of positions used during 3 separate parts of the day were examined. Three approximately equal $4 \mathrm{~h}$ periods were allocated: AM (nautical twilight to 10:00 h), Mid-day (10:00 to 14:00 h) and PM (14:00 h to nautical twilight). Analysis of variance detected no difference in the mean number of positions used during the 3 time periods $\left(F_{2,138}=1.88, \mathrm{p}=0.1566\right)$. On average, a fish used $9.1 \pm 0.28$ (SE) different positions during each time period. Evaluation of the point percentage utilisation distributions indicated a relatively consistent pattern of use of positions throughout the day (Fig. 7). Thus, coral trout preferentially used a small number of positions within their home ranges, at which they were recorded for the majority of time.

A total of 568 different spatial positions were recorded during this study. Based on visual examination by SCUBA of some of the most regularly used positions, $209(36.8 \%)$ positions could be assigned to 1 of the 3 habitat types: 'shelter site' (129 positions), 'pressure/feeding site' (73 positions) or 'cleaner station' ( 7 positions). The average proportional use per fish which could be attributed to the known positions was $35.4 \% \pm 3.26$ (SE) for 'shelter sites', $24.6 \% \pm 3.25$ (SE) for 'pressure/feeding sites', and $9.2 \% \pm 2.44$ (SE) for 'cleaning stations'. There was no difference in the mean proportional use of recorded positions per individual fish for either of the 3 allocated habitat types among the 3 different day-time periods examined (AM, Mid-day and PM; Table 3). 

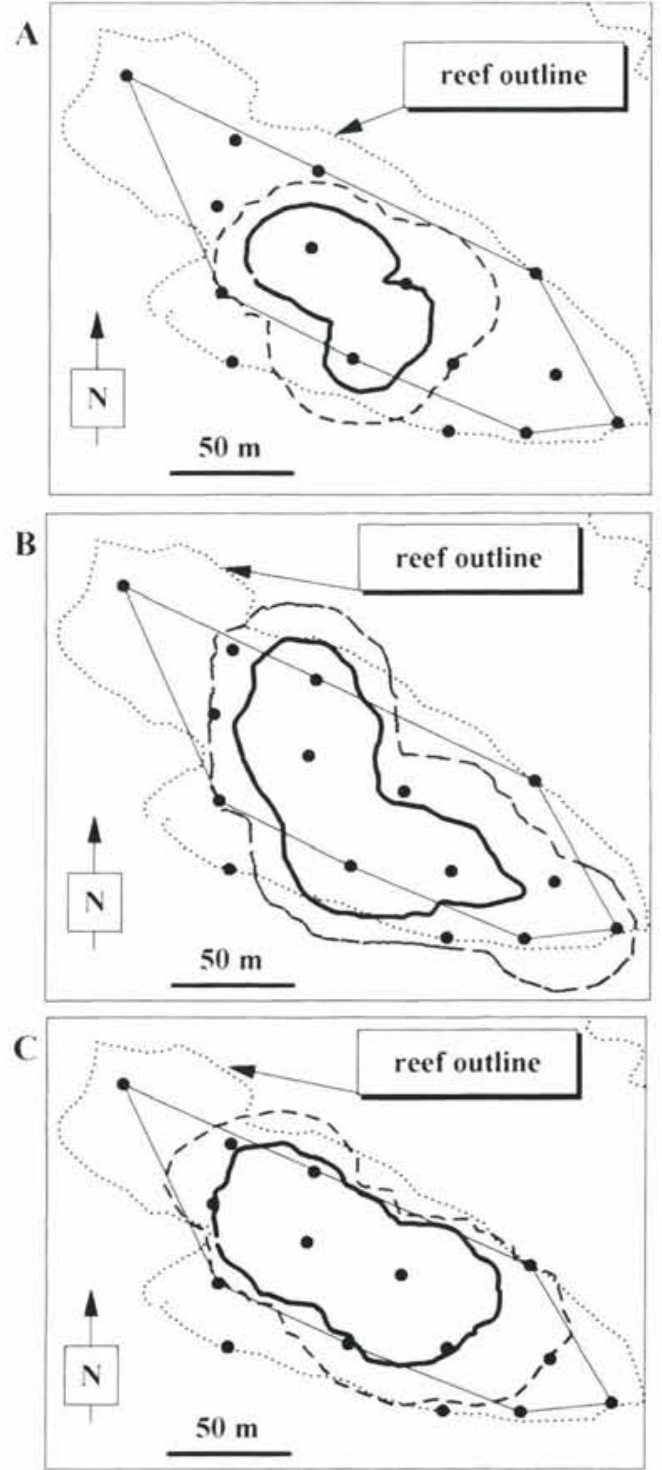

Fig, 7. Plectropomus leopardus. Percentage utilisation distributions of core area of activity for a typical individual, separated by time of day. Polygon home range is indicated also. Dotted lines: reef contour outlines. (-) Position records. Dashed lines: $75 \%$ utilisation distribution contour. Solid lines: $50 \%$ utilisation distribution contour. (A) Morning (nautical twilight to $10: 00 \mathrm{~h})$. (B) Mid-day (10:00 to 14:00 h). (C) Afternoon (14:00 $\mathrm{h}$ to nautical twilight)

\section{Distances moved}

The ultrasonic tracking data indicated that the average distance moved by an individual Plectropomus leopardus per day within its home range was $192.2 \mathrm{~m} \pm$ 5.09 (SE) (range: 0 to $1121.8 \mathrm{~m}$ ). The estimates obtained represent the minimum distance moved by an individual per day, and were based on position records obtained during the day. There was no difference in

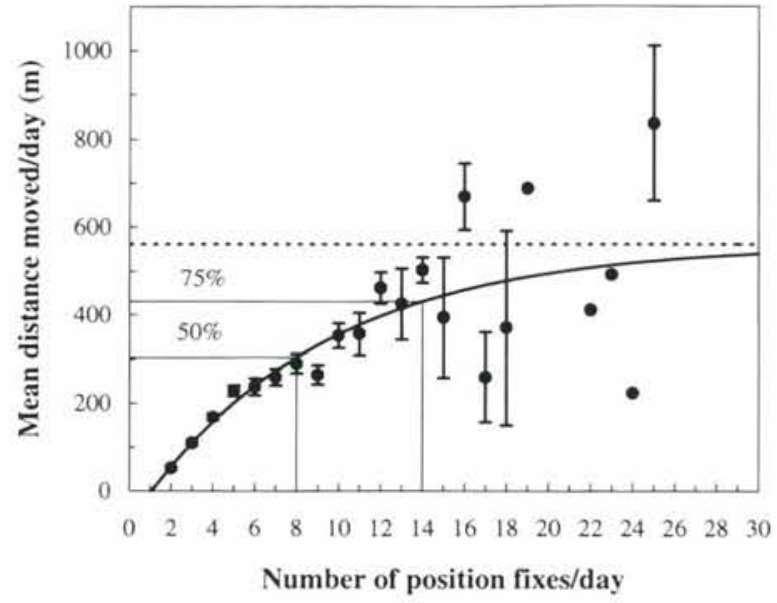

Fig. 8. Plectropomus leopardus. Effect of increasing sample size (number of position fixes per day) on the estimates of mean daily distance moved $( \pm \mathrm{SE})$ obtained from ultrasonic tracking records. Data suggested a potential asymptotic relationship, with a potential asymptotic mean daily distance moved of $560.6 \mathrm{~m}$ (dashed line). Sampling efforts to obtain $75 \%$ and $50 \%$ of estimated asymptotic mean daily distance moved are indicated also

the mean distance moved per day between fish from patch or fringing reefs $\left(t_{1179}=1.44, p=0.149\right)$, despite the observed difference in home range areas noted above.

Evaluation of the effect of sample size (number of position fixes per day) on the calculated daily distances moved within home ranges indicated the potential for an asymptotic relationship $(\mathrm{R}=0.7325)$, with a potential asymptotic daily distance moved of $560.6 \mathrm{~m}$ (Fig. 8). Clearly this does not represent the maximum mean daily distance moved, which was recorded as $835.5 \mathrm{~m} \pm 175.5$ (SE) (Fig. 8). Note that the sample sizes for distance estimates based on $>15$ fixes per day were small (i.e. $\leq 2$ records per data point). However, based on this relationship, one could assume that, on average, an estimate of $50 \%$ and $75 \%$ of daily movement distances could be obtained with 8 and 14 position fixes per day (Fig. 8).

\section{Persistence of home ranges through time}

The spatial persistence of home ranges through time was evaluated for each tracking session using linearity ratios for each individual. The mean linearity ratio $( \pm \mathrm{SE}$ ) was $0.036 \pm 0.011$ (range: 0.00 to $0.480, n=47$ ), indicating that most of the regular movements recorded were back and forth rather than unidirectional. There was no difference between fish from fringing and patch reefs $\left(t_{45}=1.725, p=0.091\right)$. Clearly, there was no shift in home ranges by individual fish 
during each tracking session. Comparisons of the home ranges for each of the 8 fish tracked on 2 separate occasions indicated almost complete overlap of ranges between tracking sessions (Fig. 9). This observation was also supported by the low linearity ratios of combined observations from both tracking periods for each fish, with a mean $( \pm$ SE) of $0.020 \pm 0.015$ (range 0.00 to 0.118 ). Linearity values did not differ between multiple tracked and single tracked fish $\left(t_{37}=0.523, \mathrm{p}=0.904\right)$. Thus, home ranges were stable within and between each tracking session.

\section{DISCUSSION}

This study demonstrates the actual sizes of home ranges of Plectropomus leopardus for the first time. Furthermore, it illustrates that different reef types
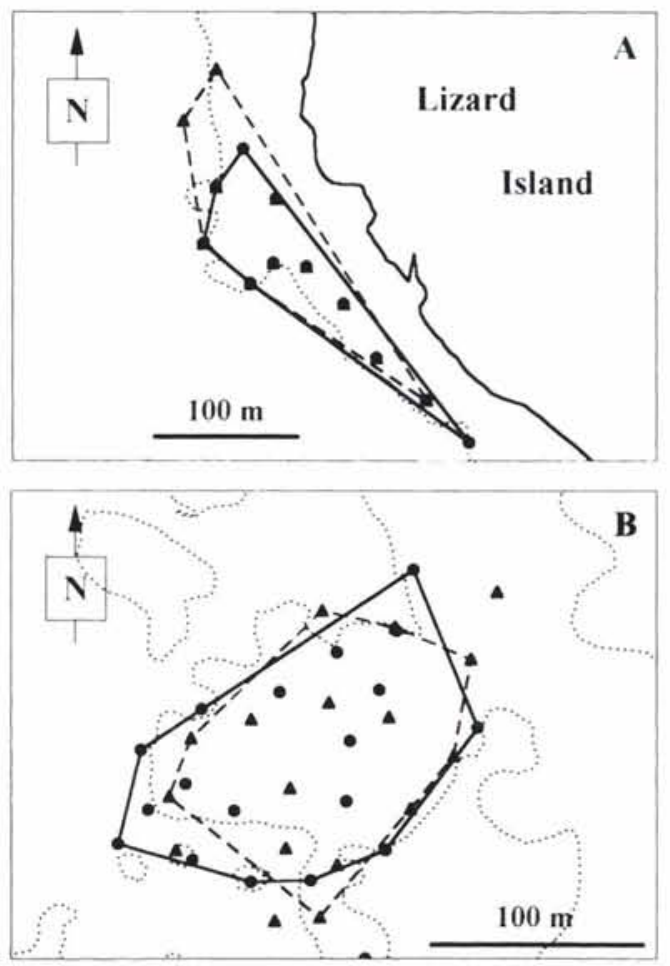

Fig. 9. Plectropomus leopardus. Maps illustrating the stability of home ranges through time for representative individuals tracked by ultrasonic telemetry over 2 separate sampling periods. Dotted lines indicate reef contour outlines. (A) Polygon home range outlines of a specimen tracked during 1994 $(\bullet-)$ and $1995(\bullet)$. Time period between successive tracking periods: $91 \mathrm{~d}$. (B) Polygon home range outlines of a

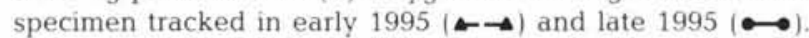

Time period between successive tracking periods: $202 \mathrm{~d}$ (patch or fringing reef) influence the size and shape of home ranges of coral trout. Limited home range information is available for only a few of the larger serranids which are of significance to fisheries. Based on visual observations of 22 tagged individuals within a $100 \times 100 \mathrm{~m}$ grid over a $152 \mathrm{~d}$ period, Shapiro et al. (1994) estimated the home ranges of Epinephelus guttatus on inshore reefs in Puerto Rico as 112 to $5636 \mathrm{~m}^{2}$. Their estimates were based on fish measuring 12.4 to $29.8 \mathrm{~cm} \mathrm{SL}$, with individual sample sizes of 13 to 57 position records per fish. Given the sensitivity of the polygon home range method in relation to small sample size (White \& Garrott 1990), these area estimates should be considered underestimates of the true home range areas. Goeden (1978) reported the largest estimates of area of use for $P$. leopardus as approximately $1200 \mathrm{~m}^{2}$, based on short term visual observations ( 7 to $120 \mathrm{~min})$. Samoilys (1987), on the basis of a visual resighting study within a limited area, suggested that the range of movements of coral trout were limited over distances of approximately $2 \mathrm{~km}$ along the reef slope, and proposed that the likely home ranges of coral trout might be larger than $4000 \mathrm{~m}^{2}$. Thus, the considerably larger home range areas documented for $P$. leopardus in the present study illustrate the limitations of SCUBA-based visual estimations of home ranges for large reef fishes.

No difference in the home range parameters between male and female Plectropomus leopardus was recorded. Different sized home ranges for males and females have been described for smaller, often territorial serranids, with females having smaller home ranges than males, e.g. Cephalopholis miniata (Shpigel \& Fishelson 1991b). However, no such relationship has been determined for larger serranids. The home range investigation reported by Shapiro et al. (1994) studied only female fish, while Carter et al. (1994) did not report whether any differences existed between the 2 females and 1 male specimen investigated.

Of particular interest is the observation that body size of coral trout did not contribute significantly to the 
variation in home ranges, at least within the size range investigated in this study ( 37.6 to $67.5 \mathrm{~cm} \mathrm{FL).} \mathrm{A}$ similar result was obtained for smaller Epinephelus guttatus (Shapiro et al. 1994), while Samoilys (1987) recorded larger individuals of Plectropomus leopardus to have larger areas of short-term movements, based on 15 min visual observation periods. The relationship between home range and body size has been examined in relatively few studies of fish, with most work done in freshwater systems (Grant \& Kramer 1990, Minns 1995). The extensively studied small coral reef labrid Thalassoma bifasciatum showed a clear, positive correlation between home range size and body size (Fitch \& Shapiro 1990). Such positive correlations were demonstrated also for juvenile lemon sharks (Morrissey \& Gruber 1993). Thus, while correlations between body size and home range exist for many fishes, current data do not support this notion for adult large serranids.

\section{Patterns of use of home ranges}

The home ranges recorded for Plectropomus leopardus were observed to be stable within as well as between consecutive sampling trips. This suggests that, for the time periods examined in this study (maximum $202 \mathrm{~d}$ between sampling trips), coral trout maintained stable areas of activity, and did not show any dispersion or turnover. Over the $3 \mathrm{yr}$ time span of this study, contact was lost with 11 coral trout equipped with transmitters. The majority of the 11 'Iosses' could be accounted for through physical rejections of transmitter units ( $\mathrm{n}=4$ ), battery and/or electronic failure $(\mathrm{n}=2)$, or inter-reef movements associated with annual spawning aggregations ( $\mathrm{n}=3$; Zeller 1997). Only 2 specimens remained unaccounted for. It has been suggested that other serranids may shift their home ranges over time (Bardach 1958, Shapiro et al. 1994). The very low linearity ratios recorded for $P$. leopardus, both within and between trips, supports the notion that most of the recorded movements were back and forth within a limited area, rather than directional. Linearity values calculated for juvenile lemon sharks inhabiting a shallow lagoon (mean linearity $=0.044$ ) also indicated high rates of revisitation to a preferred area (Morrissey \& Gruber 1993).

All Plectropomus leopardus which were tracked in this study showed preferences for a small number of positions within their home ranges. While $P$. leopardus is generally thought to be relatively site-attached, detailed information regarding use of locations within home ranges was lacking. Some investigations have attempted to address basic movements of coral trout, but were either limited to visual observations over short time periods (with associated diver disturbance of the specimens; Goeden 1978, Samoilys 1987), or they relied on chance recaptures of tagged individuals (Davies 1995). The relatively sedentary behaviour recorded in this study for $P$. leopardus corresponds to observations that large coral trout often remain at single locations for extended periods (Samoilys 1987). In the Caribbean, Epinephelus guttatus was observed also to remain at 1 location for extended times (Shapiro et al. 1994). Studies of temperate marine and freshwater fishes using ultrasonic telemetry have found also that individuals regularly spend the majority of their time in a small core area of their home ranges (Mesing \& Wicker 1986, Bradbury et al. 1995). Evolutionary advantages of prolonged use of preferred locations by $P$. leopardus may include reduced risk of predation due to superior familiarity of local shelter sites (Fricke 1980 in Sale 1991, Bray 1981, Bradbury et al. 1995). Availability of shelter has been suggested as a major factor underlying the distribution of many fishes (Smith 1961 in Parrish 1987, Talbot 1965, Goldman \& Talbot 1976). An alternative, or additional, advantage for repeated use of known locations has been suggested in the improved fitness due to ready access to food resources whose location is known and can therefore be exploited efficiently (Covich 1976 in Bray 1981, Bradbury et al. 1995).

Most Plectropomus leopardus examined in this study showed a distinct preference for reef slope locations. This reflects earlier observations that highest densities of coral trout were recorded on the reef slopes (Choat 1968, Kingsford 1992). Thus, while the total size of the observed home ranges indicated that $P$. leopardus regularly utilised substantial areas of their local reef habitat, their preference for a small number of slope positions suggests considerable local site-attachment. While it was not possible to assign a habitat type to each recorded position, the results indicate that over $50 \%$ of the records were obtained from 'shelter' and 'pressure/feeding' sites, the majority of which (35.4\%) were considered predominantly 'shelter' locations. Serranids have been shown to make regular use of shelter, and are generally dependent on hard substrata (Williams 1991, Shapiro et al, 1994). Significantly, Parrish (1987) suggested that, based on the relative breadth of diet shown by many serranids, habitat reliance is based more on shelter than on prey distribution.

The low level of activity of Plectropomus leopardus during nocturnal periods in this study supports the earlier studies of visual observation on Plectropomus spp. (Choat 1968, Johannes 1988). Carter et al. (1994) indicated that Nassau grouper were most active immediately following sunrise and just prior to sunset, and remained inactive at night. 


\section{Conclusions and management implications}

It is demonstrated that ultrasonic telemetry is the most suitable tool for evaluation of home ranges and movements of large reef fishes. While individual Plectropomus leopardus regularly utilise home range areas of several thousand $\mathrm{m}^{2}$, the majority of time is spent at a small number of locations. Furthermore, home ranges of individual coral trout are persistent through time, for the time period examined. Movements within established home ranges regularly span 200 to $300 \mathrm{~m}$. The shape and sizes of home ranges are influenced strongly by the type of reef inhabited, and no sex-specific differences exist. Available reef area appears to be the major factor which determines home ranges for P. leopardus.

The information obtained in this study provides the fundamentals for future ecological and behavioural investigations, and may serve as a foundation for the development of improved management strategies for long-term sustainable fisheries on coral reefs. Recently, increasing interest in the possible use of marine reserves as the potentially most viable strategy for sustainable coral reef fisheries management has been expressed worldwide (Alcala \& Russ 1990, Bohnsack 1990, 1993, Polacheck 1990, DeMartini 1993, Rowley 1994, Russ \& Alcala 1996a, b). Public acceptability of such a strategy relies on the determination of potential flux rates of target species across reserve boundaries and the impact of such fluxes on local fisheries yield (Alcala \& Russ 1990, Bohnsack 1990, Russ \& Alcala 1996a, b). Transfer rates of animals between protected and unprotected areas are influenced to a large extent by the boundary permeability (Buechner 1987) and the size of the protected area relative to the normal movement patterns and home ranges of the target species (Holland et al. 1993a, 1996). One of the most basic parameters of the concept of flux rates is the principle of home range size, as well as basic activity and movement patterns (Minns 1995). Thus, the home range estimates and daily movements of Plectropomus leopardus reported here provide the first step in gaining insights into the estimation of potential flux rates of this species in relation to marine reserves.

Acknowledgements. I sincerely thank Dr G. R. Russ, 1. Stobutzki, R. Retallick, K. Vernes and the reviewers for providing valuable criticism of the manuscript. 1 am indebted to numerous persons for assistance with field work, in particular $M$. Mackie, B. Cook, J. Colquhoun, B. Smith, M. Bird, B. Smalley and C. Eros. This research was funded by the Australian Museum, the Lizard Island Reef Research Foundation through the Lizard Island Doctoral Fellowship, and the Australian Research Council. Logistic support was provided by the Department of Marine Biology, James Cook University. This paper is a contribution from the Lizard Island Research Station, a facility of the Australian Museum.

\section{LITERATURE CITED}

Alcala AC, Russ GR (1990) A direct test of the effects of protective management on abundance and yield of tropical marine resources. J Cons Int Explor Mer 46:40-47

Andrew NL, Mapstone BD (1987) Sampling and the description of spatial pattern in marine ecology. Oceanogr Mar Biol Annu Rev 35:39-90

Bardach JE (1958) On the movements of certain Bermuda reef fishes. Ecology 39:139-146

Beinssen K (1989) Heron Reef demersal reef fish movement study. Interim report. Report for the Dept of Conservation, Parks \& Wildlife, Queensland, Australia

Bohnsack JA (1990) The potential of marine fishery reserves for reef fish management in the US Southern Atlantic. NOAA Tech Memo NMFS-SEFC-261

Bohnsack JA (1993) Marine reserves: they enhance fisheries, reduce conflicts, and protect resources. Oceanus 36(3): $63-71$

Bradbury C, Green JM, Bruce-Lockhart M (1995) Home range of female cunner, Tautogolabrus adspersus (Labridae), as determined by ultrasonic telemetry. Can J Zool 73:1268-1279

Bray RN (1981) Influence of water currents and zooplankton densities on daily foraging movements of blacksmith, Chromis punctipinnis, a planktivorous reef fish. Fish Bull US 78(4):829-841

Buechner M (1987) Conservation in insular parks: simulation models of factors affecting the movement of animals across park boundaries. Biol Cons 41:57-76

Cameron GN, Spencer SR (1985) Assessment of space-use patterns in the hipid cotton rat (Sigmodon hipidus). Oecologia 68:133-139

Carter J (1988) Grouper mating ritual on a Caribbean reef. Underw Nat 17:8-11

Carter J, Marrow GL, Pryor V (1994) Aspects of the ecology and reproduction of Nassau grouper, Epinephelus striatus, off the coast of Belize, Central America. Proc Gulf Caribb Fish Inst 43:65-111

Choat JH (1968) Feeding habits and distribution of Plectropomus maculatus (Serranidae) at Heron Island. Proc R Soc Queensl 80(2):13-18

Danielson BJ, Swihart RK (1987) Home range dynamics and activity patterns of Microtus ochrogaster and Synaptomys cooperi in Syntopy. J Mammal 68(1):160-165

Davies CR (1995) Patterns of movement of three species of coral reef fish on the Great Barrier Reef. PhD dissertation, James Cook University, Townsville

DeMartini EE (1993) Modeling the potential of fishery reserves for managing Pacific coral reef fishes. Fish Bull US 91(3):414-427

Ferreira BP (1995) Reproduction of the common coral trout Plectropomus leopardus (Serranidae: Epinephelinae) from the central and northern Great Barrier Reef, Australia. Bull Mar Sci 56(2):653-669

Fitch WTS, Shapiro DY (1990) Spatial dispersion and nonmigratory spawning in the bluehead wrasse (Thalassoma bifasciatum). Ethology 85:199-211

Goeden G (1978) A monograph of the coral trout. Queens] Fish Serv Res Bull 1

Goldman B, Talbot FH (1976) Aspects of the ecology of coral reef fishes. In: Jones OA, Endean R (eds) Biology and geology of coral reefs, 1st edn. Academic Press, New York, p $125-154$

Grant JWA, Kramer DL (1990) Territory size as a predictor of the upper limit to population density of juvenile salmonids in streams. Can J Fish Aquat Sci 47:1724-1737 
Gregory PT, Macartney JM, Larsen KW (1987) Spatial patterns and movements. In: Siegel RA, Collins JT, Novak SS (eds) Snakes ecology and evolutionary biology, 1st edn. Macmillan, New York, p 366-395

Hobson ES (1974) Feeding relationships of teleostean fishes on coral reefs in Kona, Hawaii. Fish Bull US 71(4): 915-1031

Holland KN, Brill R, Ferguson S, Chang R, Yost R (1985) A small vessel technique for tracking pelagic fish. Mar Fish Rev $47(4): 26-32$

Holland KN, Lowe CG, Peterson JD, Gill A (1992) Tracking coastal sharks with small boats: hammerhead shark pups as a case study. Aust J Mar Freshwat Res 43:61-66

Holland KN, Lowe CG, Wetherbee BM (1996) Movements and dispersal patterns of blue trevally (Caranx melampygus) in a fisheries conservation zone. Fish Res (Amst) 25: $279-292$

Holland KN, Peterson JD, Lowe CG, Wetherbee BM (1993a) Movements, distribution and growth rates of the white goatfish Mulloides flavolineatus in a fisheries conservation zone. Bull Mar Sci 52(3):982-992

Holland KN, Wetherbee BM, Peterson JD, Lowe CG (1993b) Movements and distribution of hammerhead shark pups on their natal grounds. Copeia 1993(2):495-502

Jennrich RI, Turner FB (1969) Measurement of non-circular home range. J Theor Biol 22:227-237

Johannes RE (1988) Spawning aggregation of the grouper, Plectropomus arelatus (Ruppel) in the Solomon Islands. Proc 6th Int Coral Reef Symp. Townsville, Australia 2 $751-755$

Keeley ER, Grant JWA (1995) Allometric and environmental correlates of territory size in juvenile Atlantic salmon (Salmo salar). Can J Fish Aquat Sci 52:186-196

Kenward R (1987) Wildlife radio tagging. Academic Press, London

Kie JG, Baldwin JA, Evans CJ (1996) CALHOME: a program for estimating animal home ranges. Wildl Soc Bull 24: $342-344$

Kingsford MJ (1992) Spatial and temporal variation in predation on reef fishes by coral trout (Plectropomus leopardus Serranidae). Coral Reefs 11:193-198

Mesing CL, Wicker AM (1986) Home range, spawning migrations, and homing of radio tagged Florida largemouth bass in two central Florida lakes. Trans Am Fish Soc 115: 286-295

Minns CK (1995) Allometry of home range size in lake and river fishes. Can J Fish Aquat Sci 52:1499-1508

Moe MA (1969) Biology of the red grouper Epinephelus morio (Valenciennes) from the eastern Gulf of Mexico. Prof Papers Series 10, Florida Dept of Natural Resources, Marine Research Laboratory, St Petersburg

Morrissey JF, Gruber SH (1993) Home range of juvenile lemon sharks, Negaprion brevirostris. Copeia 1993(2): $425-434$

Mortensen DG (1990) Use of staple sutures to close surgical incisions for transmitter implants. Am Fish Soc Symp 7 $380-383$

Munro JL (1974) The biology, ecology, exploitation and management of Caribbean reef fishes. Vb. Serranidae (hinds and groupers), Res Rep Zool Dep Univ W Indies 3:1-82

Nagelkerken WP (1979) Biology of the graysby, Epinephelus cruentatus, on the coral reef of Curaçao. Stud Fauna Curaçao Other Caribb Isl 60:1-118

Nelson DR (1990) Telemetry studies of sharks: a review, with applications in resource management. In: Pratt $\mathrm{HL}$. Gruber SH, Taniuchi $\mathrm{T}$ (eds) Elasmobranchs as living resources: advances in the biology, ecology, systematics, and the status of the fisheries. NOAA Tech Rep: NOAANMFS-SWFSC-90

Parrish JD (1987) The trophic biology of snappers and groupers. In: Polovina JJ, Ralston S (eds) Tropical snappers and groupers. Biology and fisheries management. Westview Press, Boulder, p 405-463

Polacheck T (1990) Year round closed areas as a management tool. Nat Res Model 4(3):327-354

Randall JE (1963) An analysis of the fish populations of artificial and natural reefs in the Virgin Islands. Caribb J Sci 3 : $31-47$

Robertson DR, Gaines SD (1986) Interference competition structures habitat use in a local assemblage of coral reef surgeonfishes. Ecology 67:1372-1383

Rowley RJ (1994) Marine reserves in fisheries management. Aquat Conserv 4:233-254

Russ GR, Alcala AC (1996a) Do marine reserves export adult fish biomass? Evidence from Apo Island, central Philippines. Mar Ecol Prog Ser 132:1-9

Russ GR, Alcala AC (1996b) Marine reserves: rates and patterns of recovery and decline of large predatory fish. Ecol Appl 6(3):947-961

Sadovy Y (1994) Grouper stocks of the western central Atlantic: the need for management and management needs. Proc Gulf Caribb Fish Inst 43:43-64

Sale PF (1991) The ecology of fishes on coral reefs, 1st edn. Academic Press, San Diego

Samoilys MA (1987) Aspects of the behaviour, movements and population density of Plectropomus leopardus (Lacepede) (Pisces: Serranidae) at Heron Island reef, southern Great Barrier Reef, Australia. MSc thesis, University of Queensland

Shapiro DY (1986) Intragroup home ranges in a female biased group of a sex-changing fish. Anim Behav 34:865-870

Shapiro DY, Garcia-Moliner G, Sadovy Y (1994) Social system of an inshore stock of the red hind grouper, Epinephelus guttatus (Pisces: Serranidae). Environ Biol Fish 41:415-422

Shpigel M. Fishelson L. (1989a) Food habits and prey selection of three species of groupers from the genus Cephalopholis (Serranidae: Teleostei). Environ Biol Fish 24:67-73

Shpigel M, Fishelson L (1989b) Habitat partitioning between species of the genus Cephalopholis (Pisces, Serranidae) across the fringing reef of the Gulf of Aqaba (Red Sea). Mar Ecol Prog Ser 58:17-22

Shpigel M, Fishelson L (1991a) Experimental removal of piscivorous groupers of the genus Cephalopholis (Serranidae) from coral habitats in the Gulf of Aqaba (Red Sea). Environ Biol Fish 31:131-138

Shpigel M, Fishelson L (1991b) Territoriality and associated behaviour in three species of the genus Cephalopholis (Pisces: Serranidae) in the Gulf of Aqaba, Red Sea. J Fish Biol 38:887-896

Sokal RR, Rohlf FJ (1981) Biometry. The principles and practice of statistics in biological research, 2nd edn. Freeman \& Co, New York

Springer VG, McErlean AJ (1962) A study of the behaviour of some tagged south Florida coral reef fishes. Am Midl Nat $67: 386-397$

Talbot FH (1965) A description of the coral structure of Tutia Reef (Tanganyika Territory, East Africa) and its fish fauna. J Zool 145:431-470

Thompson R, Munro JL (1978) Aspects of the biology and ecology of Caribbean reef fishes: Serranidae. J Fish Biol 12:115-146

Todd IA (1993) WILDTRACK: non-parametric home range analysis for the Macintosh. User's guide. Dept of Zoology, University of Oxford 
Tulevech SM, Recksiek CW (1994) Acoustic tracking of adult white grunt, Haemulon plumieri, in Puerto Rico and Florida. Fish Res (Amst) 19:301-319

Underwood AJ (1981) Techniques of analysis of variance in experimental marine biology and ecology. Oceanogr Mar Biol Annu Rev 19:513-605

White GC, Garrott RA (1990) Analysis of wildlife radio-tracking data, 1st edn. Academic Press, San Diego

Williams DMcB (1991) Patterns and processes in the distribution of coral reef fishes In: Sale PF (ed) The ecology of fishes on coral reefs, 1st edn. Academic Press, New York, p 437-474

Williams DMcB, Russ GR (1994) Review of data on fishes of

This article was submitted to the editor commercial and recreational fishing interest on the Great Barrier Reef. Great Barrier Reef Marine Park Authority Res Publ 33

Winter JD, Ross MJ (1982) Methods in analyzing fish habitat utilization from telemetry data. In: Armantrout N (ed) Proc Symposium Acquisition and Utilization of Aquatic Habitat Inventory Information. Am Fish Soc West Div, p 273-279

Worton BJ (1987) A review of models of home range for animal movement. Ecol Model 38:277-298

Zeller DC (1997) Patterns of movement of Plectropomus leopardus (Serranidae) in relation to spawning aggregations and marine protected areas, as determined by ultrasonic telemetry. PhD thesis, James Cook University, Townsville

Manuscript received: March 24, 1997

Revised version accepted: June 4, 1997 